\title{
Relações entre dois pedaços de Buenos Aires moderna: os planos não construídos de Antonio Bonet Castellana para Bajo Belgrano (1948-1949) e para Barrio Sur (1956)
}

BENDER, Helena

\begin{abstract}
Resumo
Ainda que os planos para Bajo Belgrano (19481949) e para Barrio Sur (1956) não tenham sido construídos, eles colocam uma sequência importante ao estudo da cidade moderna e à carreira de Antonio Bonet Castellana. Trata-se de planos para novos bairros em Buenos Aires, nos quais a habitação é reconhecida como programa capaz de renovação urbana, tanto de áreas que eram pouco formalizadas, no caso de Bajo Belgrano, como de áreas tradicionalmente constituídas ainda que subutilizadas como em Barrio Sur. Os planos para Bajo Belgrano e Barrio Sur são discursos distintos. Mas existiriam componentes intercambiáveis entre essas proposições? Estudos recentes têm investigado ambos os planos separadamente e pouco se têm discutido sobre as relações entre eles, possíveis através do personagem comum Antonio Bonet Castellana. Este texto tem por objetivo confrontar estes planos, explorando suas diferenças e semelhanças, suas relações com a cidade existente, bem como suas contribuições ao conhecimento sobre a cidade moderna.
\end{abstract}

Palavras-chave: Bajo Belgrano. Barrio Sur. Antonio Bonet Castellana. Cidade Moderna. Habitação Coletiva.

\begin{abstract}
:
Even though the plans for Bajo Belgrano (194849) and Barrio Sur (1956) were never put into practice, they offer an important continuation to the study of the modern city and to Antonio Bonet Castellana's career. Both plans propose new districts in Buenos Aires, following the notion that housing is a program capable of urban renewal; such renewal could affect both little formalized areas like Bajo Belgrano and traditionally constituted but underused areas like Barrio Sur. Despite conveying two different discourses, could there be interchangeable components among them? Recent studies have investigated them separately and little has been discussed about the relationship between them, made possible by their common character, Antonio Bonet Castellana. This text aims to compare these plans, exploring their differences and similarities, their relationship with the existing city, and their contributions to knowledge of the modern city.
\end{abstract}

Keywords: Bajo Belgrano. Barrio Sur. Antonio Bonet Castellana. Modern City. Collective Housing. 


\section{Introdução}

Em duas entrevistas concedidas no início da década de 1980, respectivamente para as revistas Summa e Dos Puntos, Antonio Bonet Castellana relata os planos não construídos para Bajo Belgrano (1948-1949) e para Barrio Sur (1956) em sequência, explicando-os como trabalhos relacionados. Trata-se de planos para novos bairros em Buenos Aires, nos quais a habitação é reconhecida como programa capaz de renovação urbana, tanto de áreas que eram pouco formalizadas, no caso de Bajo Belgrano, como de áreas tradicionalmente constituídas ainda que urbanisticamente estagnadas como em Barrio Sur. Entre esta explicação não há menção aos projetos realizados em Punta Ballena (19451948), ao Conjunto habitacional TOSA (1952), ou mesmo à parceria com Ferrari Hardoy no Plano para Necochea-Quequén (1952). Entre Bajo Belgrano e Barrio Sur, Bonet coloca em evidência uma evolução crítica de determinados aspectos constituintes, alertando que no primeiro a área verde dedicada ao projeto surpreende pelo tamanho e que, para o último, o verde deixa de ser dominante para ser um dentre os demais componentes do espaço aberto projetado (apud BOBZIN, 1983, p. 45-46; apud PETRINA, 1983, p. 21).

Bajo Belgrano e Barrio Sur são também explicados em sequência um pouco mais tarde por Katzenstein et al. (1985), colocando-os como projetos vinculados com as distintas abordagens desenvolvidas dentro dos Congressos Internacionais de Arquitetura Moderna (CIAM): "Desde os edifícios soltos em jardins" como em Bajo Belgrano, até o uso da "densidade para levar a cabo propostas onde se guardava o espírito tradicional de ruas e praças, tal como em Barrio Sur" (KATZENSTEIN et al., 1985, p. 19-20, tradução nossa). Para os autores a comparação interessa, pois Barrio Sur "expressa um ponto de vista oposto [ao de Bajo Belgrano] com suas edificações contínuas e a estreita relação do setor remodelado com a cidade existente" (KATZENSTEIN et al., 1985, p. 92, tradução nossa).

Estudos recentes têm investigado Bajo Belgrano e Barrio Sur separadamente, mas com um argumento diferente ao de Katzenstein et al.: entendendo-os como proposições que apontam outras transformações a partir das noções via CIAM; e que ambos se relacionam com realidade urbana de Buenos Aires, e não só Barrio Sur. Para Ballent (2009, p. 236, tradução nossa), Bajo Belgrano "se encontra completamente afastado da repetição mecânica de 'receitas', com as quais se costuma associar a arquitetura e o urbanismo produzido ou inspirado pelos CIAM" e que a importância dada ao "estudo histórico da cidade pouco tinha que ver com um urbanismo de 'tabula rasa'". Ainda sobre Bajo Belgrano, Cabral (2010, p. 92-93) destaca o uso de equipamentos preexistentes como o Estádio do River Plate (1938), que é reconhecido no projeto "como parte ativa da composição", bem como a preocupação em formalizar um sistema de circulação pedestre. Sobre Barrio Sur, Liernur (2011, p. 91, 89, tradução nossa) o coloca como projeto em que "se considerou a resolução do problema da habitação em relação à estruturação urbana" de Buenos Aires, integrando-se à cidade existente.

Os planos para Bajo Belgrano e Barrio Sur são proposições que compreendem o imaginado no contexto urbano, como os tantos exemplos de cidade moderna que por diversos motivos ficaram sem construir. Aqui são entendidos como discursos de Antonio Bonet Castellana que se referem a dois tempos da cidade moderna, bem como a dois cenários distintos de Buenos Aires. Mas existiriam componentes intercambiáveis entre estas proposições? Este texto tem por objetivo confrontar estes planos, explorando suas diferenças e semelhanças, suas relações com a cidade existente, bem como suas contribuições ao conhecimento sobre a cidade moderna. Para tanto, o texto se estrutura por meio da comparação, apresentando Bajo Belgrano para depois explicar Barrio Sur. Aos dois projetos se procurou seguir uma descrição comum, iniciada pelo lugar em que a proposta se estabelece seguida de como ela se organiza, para então compreender seus componentes e relações mais específicas.

\section{Bajo Belgrano e a cidade sobre o verde} Bajo Belgrano é um dos trabalhos elaborados por Bonet, Jorge Ferrari Hardoy e Jorge Vivanco, em meio ao Escritório do Plano de Buenos Aires (EPBA, 1947-1949). Trata-se de uma proposta de bairro para 50.000 habitantes, número derivado de pesquisas sobre a população presente em bairros de Buenos Aires à época (ALVAREZ, 1991, p. 358; BALLENT, 2009, p. 235-236), mais precisamente nos bairros Boca, Flores e Belgrano, fazendo uso de "índices baseados na realidade" (EPBA, 1953, p. 20), para então conceber uma proposta alternativa à cidade de quadras.

$\mathrm{Na}$ época, a área destinada ao projeto, apesar de configurada pela quadra de origem espanhola, não era totalmente preenchida (Figura 1). Em frente ao Rio da Prata, a porção de 170 hectares conhecida como Bajo Belgrano e circundada pelo o que hoje são a Rua Pampa e as avenidas 
Figura 1: Área de projeto à época.

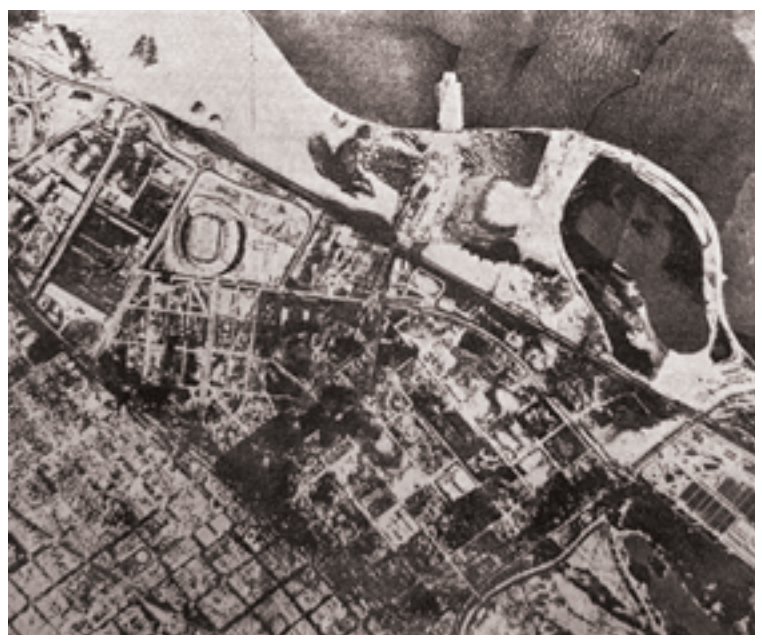

Fonte: EBPA, 1953, p. 20; 1949a.

Guillermo Udaondo, Libertador e Leopoldo Lugones, apresentava terrenos inundáveis e "com grande proporção de baldios" (EPBA, 1953, p. 21). A situação geográfica era oportuna para montar um contato direto com a natureza, recuperando o sol, o ar, a luz "com uma magnífica área de lazer e inclusive de veraneio" garantida pela proximidade com rio (EPBA, 1953, p. 21, tradução nossa). Neste sentido, as áreas dedicadas para o verde e lazer se colocam como importantes na proposta, bem como a incorporação de equipamentos urbanos preexistentes $e$ adjacentes à área de projeto, tais como o Estádio do River Plate (1938), a sede do Tiro Federal Argentino (1891) e o Projeto de Parque Costanero.

A área é subdividida pelo plano em quatro grandes porções através do prolongamento das atuais vias Juramento, Blanco Encalada e Manoel Ugarte, que servem como estrutura de vinculação entre a nova cidade e a existente, e oportunizam o desenvolvimento do trânsito veicular no interior do bairro. Tais porções não são preenchidas pelo modelo da quadra, mas sim pela transformação desta em vinte blocos habitacionais intitulados "quarteirões verticais" de 180 metros de comprimento, 18 de largura, 50 de altura e 2.300 habitantes cada (EPBA, 1953, p. 48), desenvolvidos sobre pilotis. Os blocos, ou os novos quarteirões, são implantados de modo a obter uma insolação homogênea, estabelecendo sua maior dimensão no sentido norte-sul, concordando com o Estádio preexistente, em vez de concordar com a ortogonalidade sugerida pelas vias. ${ }^{1}$ A maior densidade, próxima de $295,^{2}$ em comparação com os 66 habitantes por hectare da época (EPBA, 1953, p. 26), e a menor ocupação resultantes propiciam o desenvolvimento de áreas de lazer e de verde de modo

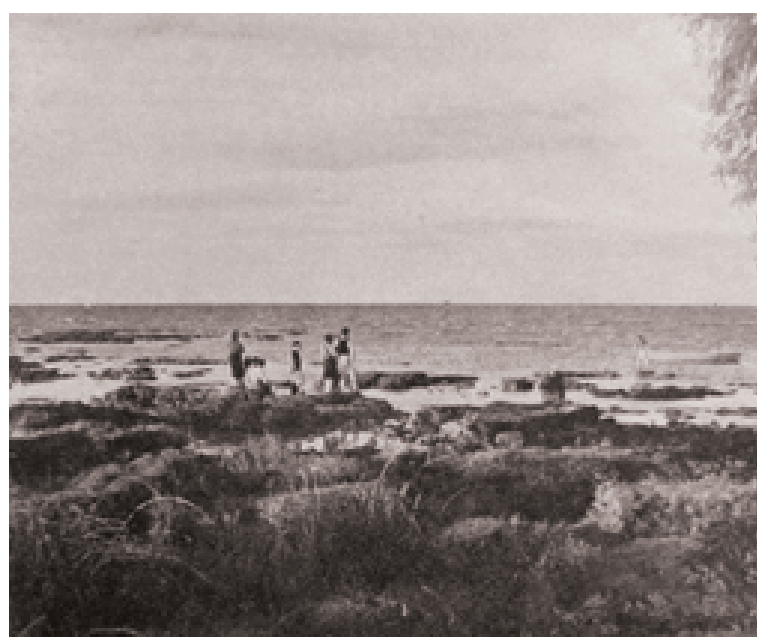

expandido, completando a operação de conversão do tecido tradicional em tecido moderno, de peças sobre o verde, exemplificada nos fotogramas do filme de divulgação "La ciudad frente al río" (1949) (Figura 2).

Contudo, em vez de confirmarem este esquema simplificado, os diferentes blocos de habitação, ou "quadras verticais", são conectados entre si por uma megaestrutura de passeios cobertos, organizada transversalmente (Figura 3). Nas palavras do grupo "estas circulações corrigem os inconvenientes que puderam produzir os grandes espaços abertos e constituem, ao mesmo tempo, um elemento indispensável à escala humana" (EPBA, 1953, p. 49, tradução nossa). Tal estrutura é preenchida por comércio e moradia desses comerciantes, e oportuniza o estabelecimento de escolas, centros de saúde, equipamentos esportivos, entre outros programas de suporte à habitação fora dos blocos, em edifícios baixos e diferenciados. A estratégia também favorece o estabelecimento de praças e explanadas com o intuito de "recuperação da tradicional função latina da praça como o centro da vida de relação" (EPBA, 1953, p. 39, tradução nossa), além da implantação de uma "Rambla de Comércios e Explanada Cívica" no centro compositivo do conjunto. Como Cabral (2010, p. 93, 96) aponta, esta soma de elementos faz de Bajo Belgrano mais crítico como solução de espaço aberto que sua simples redução à área verde.

O plano é subdividido em dez unidades menores, descritas como "unidades de vizinhança", que são reunidas a partir de dois blocos de

1. Para saber mais, ver Cabral, 2010.

2. Densidade calculada segundo o número de 50.000 habitantes e área total de 170 hectares. 
Figura 2: Fotogramas do Filme "La ciudad frente al río" (EPBA, 1949)
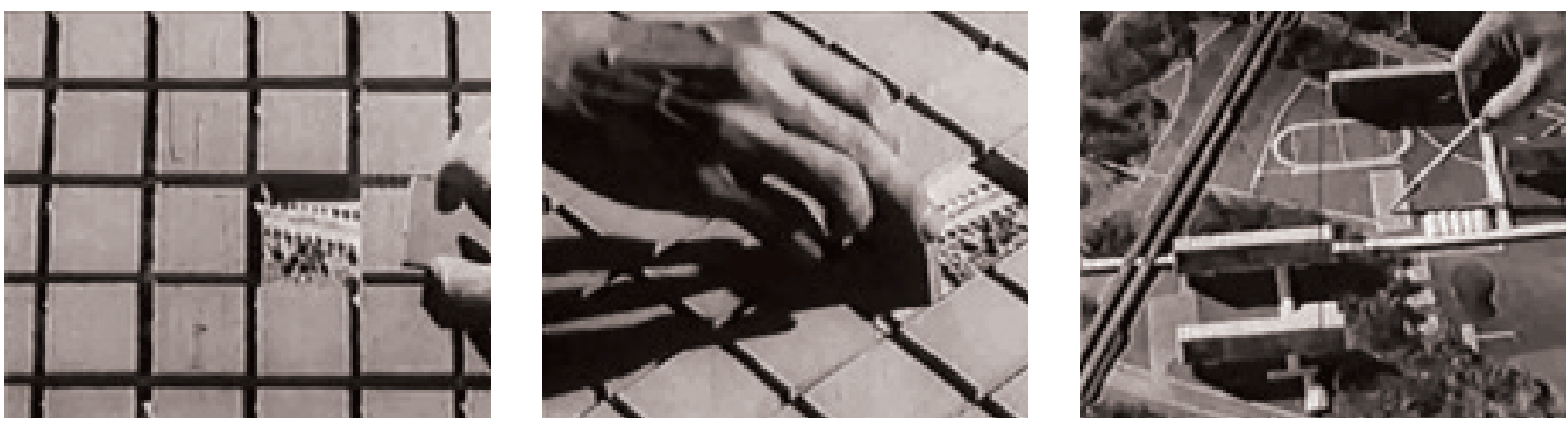

Fonte: Arquitectes: Antoni Bonet. ${ }^{3}$

habitação e um pequeno comércio (EPBA, 1953, p. 37), e não a partir de um centro escolar como sugere o CIAM via Sert (1947, p. 70). Observando apenas o bloco, percebe-se uma ativa exploração de sua seção no processo de projeto, que se dá pela investigação de duas tipologias: a do bloco escalonado, de sacadas a céu aberto e circulação horizontal aberta localizada em fachada; que evolui para o bloco reto, composto por fita dupla de unidades e circulação horizontal central, com maior possibilidade de se desenvolver em altura (EPBA, 1953, p. 49). Ambas as tipologias apresentam diversidade quanto à configuração das unidades, que se desenvolvem em duplex. Essas unidades são acessadas pelas "circulações horizontais ou 'ruas do bloco' [que] se definem pela vida a se desenvolver entre as famílias de uma quadra de bairro" (EPBA, 1953, p. 49, tradução nossa), estendendo no plano vertical os percursos pedestres iniciados no térreo.

Bajo Belgrano é apresentado no IV Congresso Interamericano (1949) e posteriormente publicado em Revista de Arquitectura (1953) como alternativa à cidade tradicional, demonstrando outras possibilidades de organização diante do aumento populacional. Por um lado, o plano é mostrado como solução à cidade com falta de sol e de ar, características associadas ao discurso CIAM (BALLENT, 2009, p. 33); a estas se poderiam somar outras, como a insistência em uma maior densidade e menor ocupação, a separação entre os trânsitos de veículos e pedestres, e a adoção da ideia de unidade de vizinhança. Por outro lado, o plano também é explicado a partir das estruturas urbanas que existem na cidade, seja a partir da quadra tradicional, que é transforma$\mathrm{da}$, ou a partir dos equipamentos preexistentes e que se vinculam à proposição. Neste sentido aqui se destacam a importância dedicada ao estudo da cidade como aponta Ballent e a crítica à ocupação do espaço aberto colocada por Cabral.

\section{Barrio Sur e a cidade sobre a cidade}

Sete anos depois de Bajo Belgrano, Bonet é convidado pelo presidente do Banco Hipotecário Nacional a "fazer e estudar um projeto com uma proposta de delimitação" (BONET apud KATZENSTEIN et al., 1985, p. 95, tradução nossa), organizando uma equipe entre oito arquitetos e doze colaboradores ${ }^{4}$ para a elaboração de um plano de reabilitação. A proposta é pensada para 450.000 habitantes, distribuídos sobre uma área de duzentos hectares próxima a Plaza de Mayo, limitada pelas avenidas Paseo Colón, 9 de Julio, Belgrano e a Rua Caseros, incluindo o preexistente Parque Lezama como área complementar (Figura 4). Diferente de Bajo Belgrano, a área de atuação de Barrio Sur não se dá sobre um terreno pouco ocupado, mas sim sobre uma das áreas mais antigas da cidade, e à época, subutilizada. Tal condição pretendia ser revertida pelo plano através do uso da habitação, defendida como programa importante para o centro da cidade.

A área limitada é dividida em seis grandes setores equivalentes, cada qual substituindo aproximadamente dezesseis quadras e abrigando 75.000 habitantes. Esta divisão é feita pela manutenção de vias existentes, sendo elas as ruas Perú, San Juan e Independencia, a manter o trânsito veicular. Ao centro de cada setor são implantados edifícios de programas especiais, áreas de lazer e de verde; para a periferia,

3. Vídeo. Disponível em: <http://www.youtube.com/ watch?v=oWTmDxevM_o>. Acesso em: nov. 2012

4. Colaboraram com Bonet: Luis H. Aberastain Oro, Horacio Baliero, Nélida Gurevich, Eduardo Polledo, Próspero E. Poyard, Victor Sigal, César A Vapñarsky e Severo A. Yantorno (arquitetos); Jorge A. Martucci (engenheiro); Osvaldo Lauersdorf (agrimensor); Eduardo Bell, Oscar N. Candioti, Raúl Pastrana (maquetes); Carmem Córdova de Baliero, Carlos Castiglione, Carlos E. Dourge, Justo J. Solsona, Fernando L. Tiscornia (desenhos). Alfredo Hlito (representação), e Aníbal G. Larumbe (fotografia) (BONET, 1957, p. 63). 

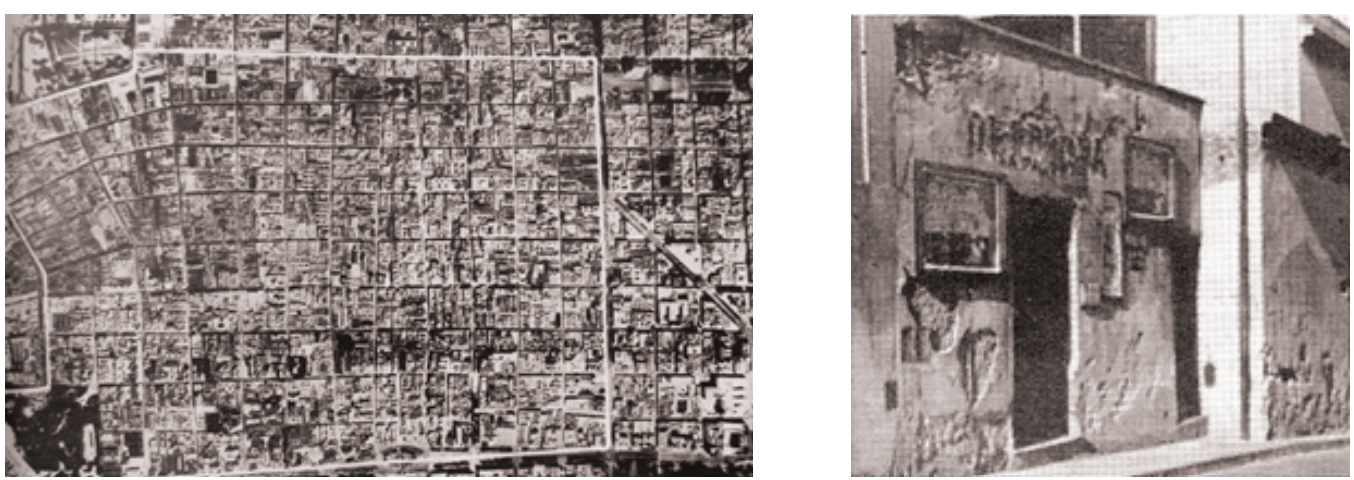

Fonte: BANCO HIPOTECARIO NACIONAL, 1957; PROJETO..., 1958, p. 28.

Figura 5: Maquete do Plano para Barrio Sur.

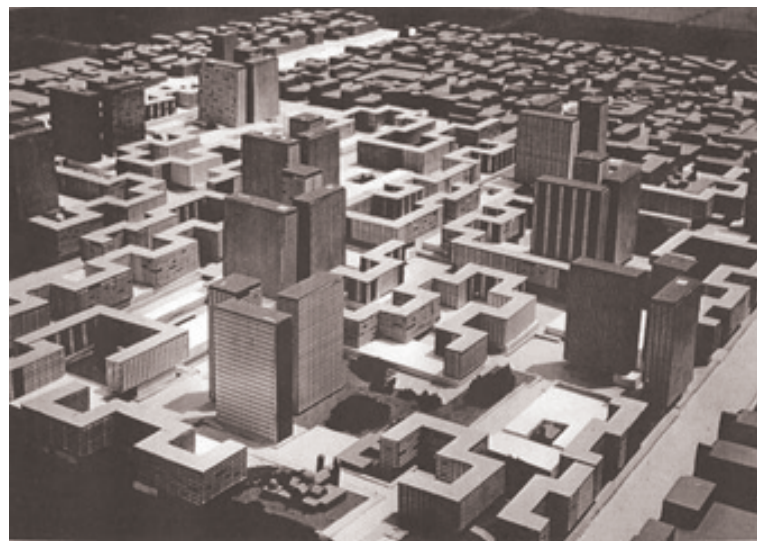

Fonte: Arquivo Histórico Colégio de Arquitetos da Catalunha. ${ }^{5}$

implanta-se o comércio, programa que configura o limite de cada um dos setores bem como a continuidade entre plano e cidade existente. Sobre esta estrutura, o que antes era ocupado pelo tecido tradicional de quadras e lotes, é rearranjado em três tipos de edifícios - a torre, de cem metros de altura; a grega, de trinta metros de altura; e o edifício baixo, de seis metros de altura. Tais edifícios organizam uma densidade de 2.250 habitantes por hectare, ${ }^{6}$ e se orientam de acordo com a lógica ortogonal colocada pela cidade existente, ou seja, segundo os eixos norte-sul e leste-oeste e não conforme uma única orientação (Figura 5).

Os três tipos de edifícios utilizados em Barrio Sur - a torre, a grega, e o edifício baixo - são vinculados entre si por uma rede de percursos pedestres que se expande por todo o plano. Esta rede não resulta do uso de um único elemento, mas sim da interação entre os três tipos de edifícios, intermediados pelo edifício baixo.

5. Disponível em <http://www.coac.es>. Acesso em: 10 fev. 2013.

6. Densidade calculada segundo o número de 450.000 habitantes e área total de 200 hectares.

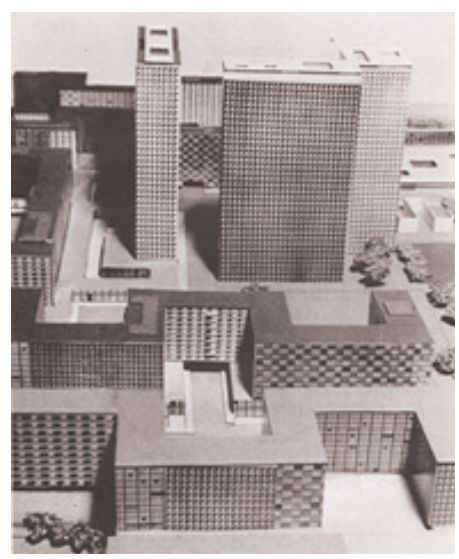

Desta manipulação de componentes resultam espaços abertos que variam desde pequenas praças até explanadas cívicas e áreas de verde, diversificação relacionada com a preocupação de Bonet (BHN, 1957) com uma maior "adequação dos espaços exteriores" (Figura 6). Associado à rede pedestre se implantam diferentes programas de suporte à habitação, tais como escolas, centros culturais e esportivos, entre outros, que animam o percurso por entre os setores do projeto. Ao centro de todo o conjunto, sobre a Rua Perú, e nas interseções desta com as avenidas Independencia e San Juan, instala-se o que Bonet (BHN, 1957) chama de "centro comercial". Elemento passível de associação com a ideia de rua comercial, que em meados da década de 1950 será característica comum entre diversos bairros de Buenos Aires (ABOY, 2010, p. 4).

Cada um dos seis setores é dividido em três "grupos de vizinhança" com 25.000 habitantes cada, dotados de comércios, uma escola e uma capela (BHN, 1957). Exceto a cifra de habitantes e o programa idealizado, esta divisão não se expressa claramente nos desenhos publicados sobre o plano, possivelmente por se tratar de 
Figura 6: Diferentes componentes do percurso pedestre.

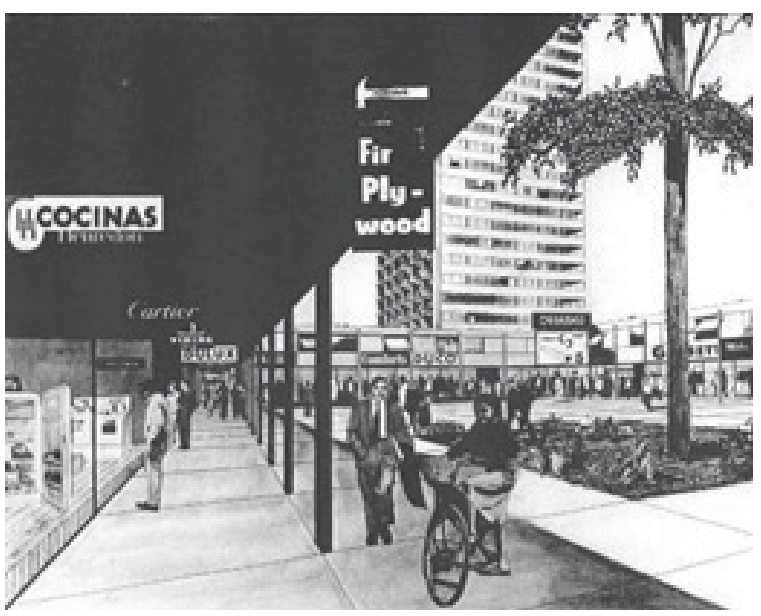

Fonte: Arquivo Histórico COAC; ${ }^{7}$ BHN, 1957.

um plano diretivo - a ser completado ao longo de dez anos de obra e por diferentes arquitetos. Dessa forma, os componentes habitacionais permanecem abstratos, com exceção de um conjunto de duas torres que Bonet teve a oportunidade de melhor definir. Em relação às torres, Bonet desenvolve os tipos norte-sul e leste-oeste, ambas retangulares, que abrigam 2.500 habitantes cada. A torre norte-sul tem as unidades organizadas em duplex, e circulação horizontal lateral, que ocupa parte da fachada orientada a sul; a torre leste-oeste tem as unidades desenvolvidas a cada piso, e circulação horizontal central, de modo a ocupar com unidades as fachadas ensolaradas a cada face do edifício. Já a grega compõe um tipo semelhante ao redent de Le Corbusier, constituindo um tecido contínuo, elevando-se sobre ruas, e se adaptando por entre as quadras adjacentes à área de projeto. Por fim, o edifício baixo é aqui entendido como uma estratégia de projeto. Por não ter uma forma definida, a existir como um retângulo, um quadrado, ou alguma forma especial, tal componente oportuniza a manutenção de edifícios existentes no interior do plano, ${ }^{8}$ bem como o controle do grande espaço aberto, regulando a área de verde dedicada à proposição.

Barrio Sur foi publicado em diversas revistas de arquitetura à época, tal como a argentina Mirador (1957), as brasileiras Módulo (1957) e Habitat (1958), e as europeias Revista Nacional de Arquitectura (1956), Bauen und Wohnen

7. Disponível em <http://www.coac.es>. Acesso em: 10 fev. 2013.

8. Bonet especifica trinta edifícios de importância histórica, artística, social e/ou econômica a serem mantidos pelo plano (BHN, 1957).

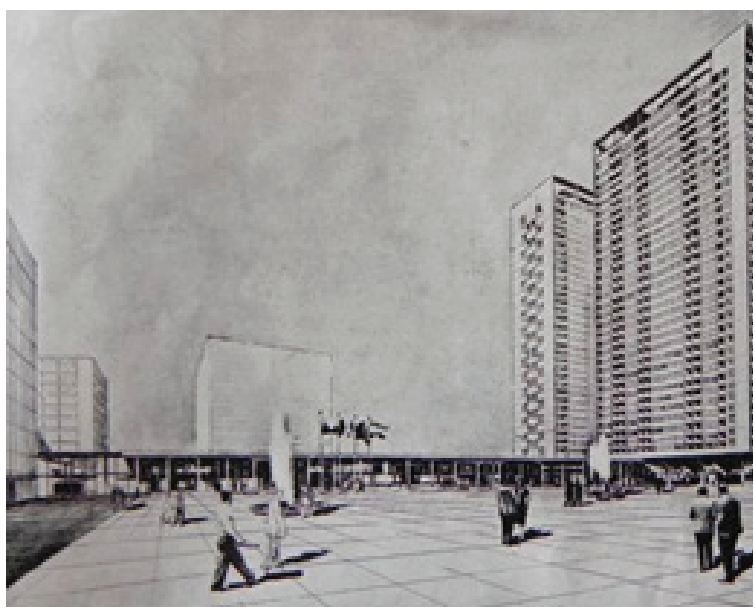

(1958), e Cuadernos de Arquitectura (1959), atingindo projeção internacional. Como vínculo ao discurso CIAM, além do mencionado para Bajo Belgrano, podem-se citar as preocupações colocadas para a $8^{a}$ edição, que evocam a importância de se atuar no centro das cidades, ou no "coração da cidade", bem como a preocupação com uma melhor adequação à escala humana (SERT apud CIAM, 1952, p. 4, 11). Porém, ao mesmo tempo, as decisões tomadas para conceber Barrio Sur travam vínculos com a cidade que existe, seja pela adoção da forma da quadra, pelo respeito a alinhamentos urbanos preexistentes, ou pela contenção das áreas de verde organizadas para o projeto.

\section{Entre Bajo Belgrano e Barrio Sur}

A justaposição entre Bajo Belgrano e Barrio Sur coloca uma pergunta metodológica: cidade, bairro, setor, ou unidade de vizinhança, em quais das medidas os planos são comparáveis? A resposta demandaria considerá-los em relação ao problema populacional que determinaram resolver (50.000-5.000/ 450.000-75.000-25.000); a área ocupada (170/ $200 \mathrm{ha}$ ); e a estrutura programática montada. Esta pergunta coloca em evidência o quão diferentes podem ser Bajo Belgrano e Barrio Sur. Entretanto o que se pretende não é equiparar os planos, mas investigá- los como estratégias de revisão da cidade existente, e que neste sentido incorporam elementos comuns. Para tanto, o primeiro movimento expresso por Bajo Belgrano e Barrio Sur é partir da estrutura urbana tradicional para então prosseguir em outra lógica (Figura 7 ).

A quadra de Buenos Aires é questionada como módulo urbano pertinente, sendo entendida por Bonet (BHN, 1957) como elemento urbanístico 
"fora de escala", e sofre transformações. Em Bajo Belgrano a organização de faixas espaçadas a cada três quadras (aproximadamente), e que não são interrompidas por todo o limite do projeto, altera a forma quadrada inicial, compondo uma parcela alongada e ampliada. Em Barrio Sur a estrutura formal da quadra é mantida, mas também se agiganta, envolvendo dezesseis quadras existentes; a ideia da quadra é trocada pela de setor, que se preenche de três tipos distintos de edifícios. A deformação da quadra em Bajo Belgrano e a ampliação desta em Barrio Sur aproximam a estrutura viária com o módulo de quatrocentos metros sugerido por Le Corbusier (1924, p. 162) como ideal para o tráfego veicular da cidade moderna. Esta nova medida interrompe a solução compartilhada entre o trânsito de carros e pedestres, que passam a se estabelecer como sistemas independentes.

Assim, tanto Bajo Belgrano quanto Barrio Sur se preocupam em montar um sistema de percursos pedestres (Figuras 8, 9), característica que não é tão comum na tradição moderna como lembra Cabral (2010, p. 93). Ainda que com estratégias distintas - Bajo Belgrano e a megaestrutura de passeios cobertos, Barrio Sur e o percurso resultante da interação entre seus edifícios componentes -, os percursos pedestres montados por ambos são preenchidos de programas animadores, como comércio, bem como de

Figura 7: Planos para Bajo Belgrano e Barrio Sur em mesma escala.
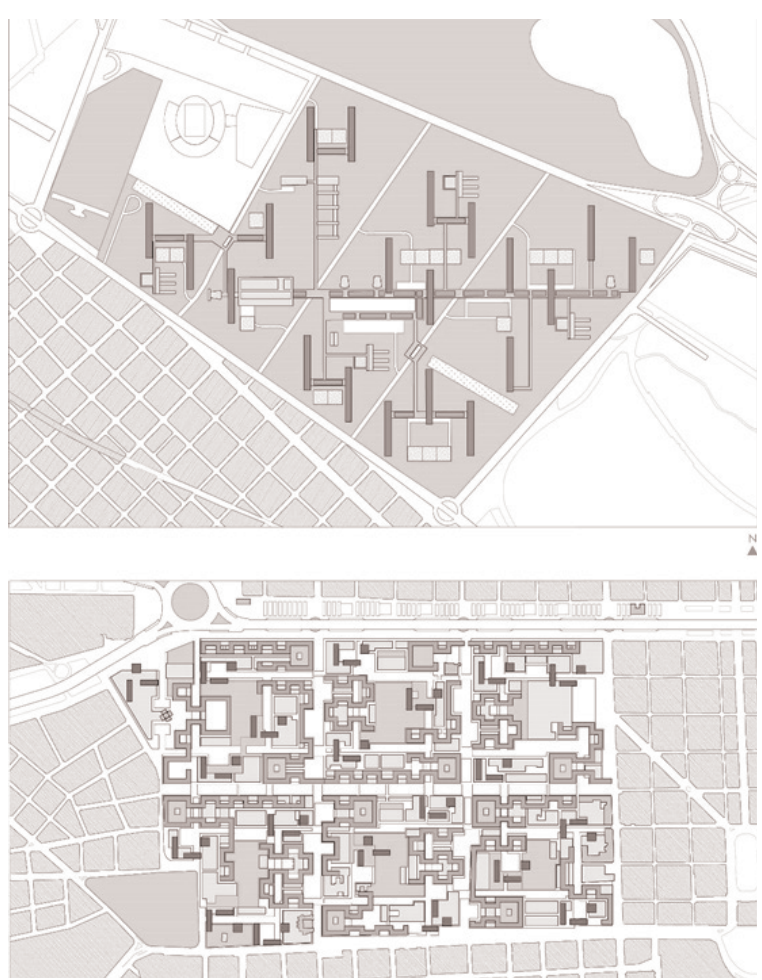

Fonte: Redesenho do autor. componentes de lazer e vida cívica, como praças e esplanadas. Existe em Bajo Belgrano e em Barrio Sur a comum associação de um componente de circulação com outros de permanência, a montar um contexto mais complexo em relação aos usos do espaço aberto e do nível térreo do que as críticas à cidade moderna costumam sugerir. E se a preocupação de Bonet com um sistema pedestre em Barrio Sur pode ser associada às discussões em meio ao CIAM VIII (1951), não explica a mesma preocupação já presente em Bajo Belgrano. Ambos os planos também preveem uma concentração comercial no centro compositivo do projeto. No caso de Bajo Belgrano, esta concentração central de serviços já era parcialmente discutida pelas proposições de Steiger e Moser (SERT, 1947, p. 71), e no caso de Barrio Sur pelas recomendações de Sert (CIAM, 1952, p. 6) em relação à ênfase aos centros de vida comunitária. Entretanto outra leitura possível de ser feita é a sensibilidade destas propostas em relação ao contexto local que se delineava, favorável ao desenvolvimento da rua comercial.

Se a montagem de uma rede pedestre aproxima Bajo Belgrano de Barrio Sur, o tratamento quanto à área de verde dedicada ao espaço aberto os diferencia, confirmando a observação de Bonet de que há uma alteração diante da relação cidade e natureza proposta. Em Bajo Belgrano a área

Figura 8: Sistemas de percursos pedestres: Bajo Belgrano (acima) e Barrio Sur (embaixo).
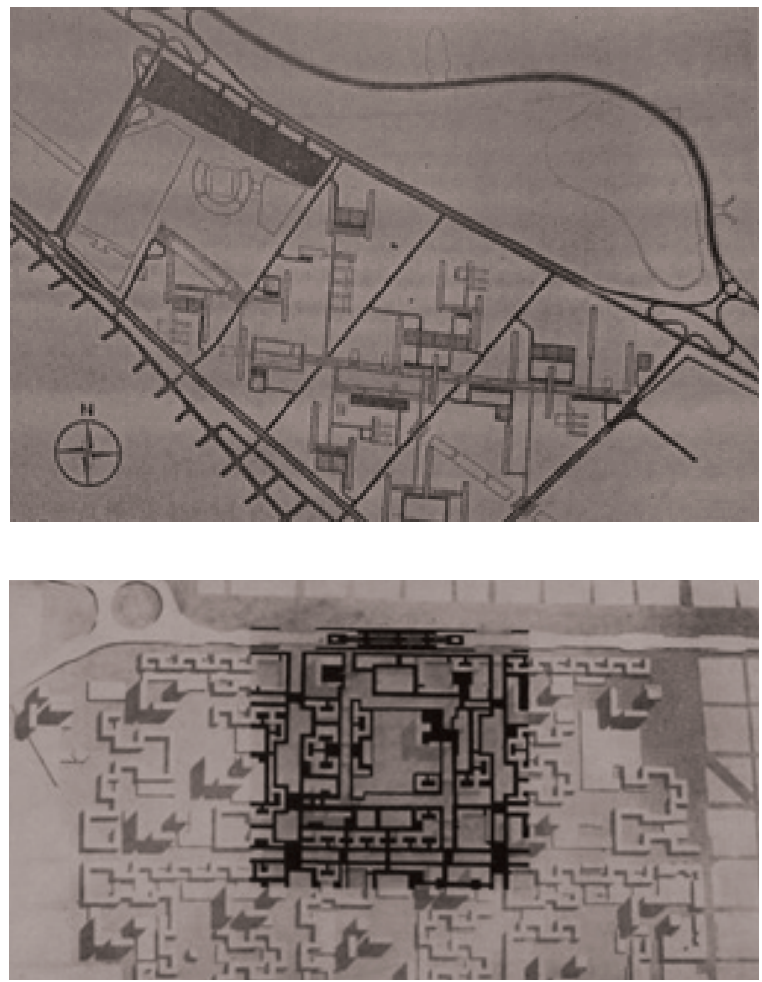

Fonte: EPBA, 1953 p. 42; Bonet, 1959, p. 10. 
Figura 9: Percurso pedestre: Bajo Belgrano (esquerda) e Barrio Sur (direita).

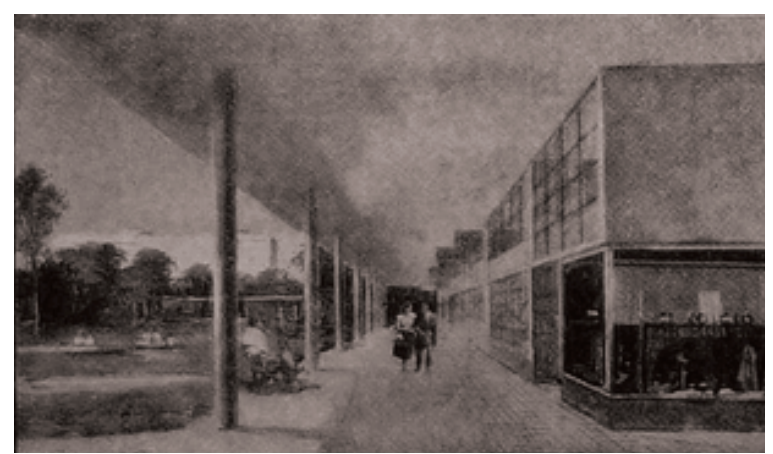

Fonte: EPBA, 1949a; Arquivo Histórico COAC.

de verde é contínua, e não se limita pelos componentes edificados do projeto, mas sim por seus limites de atuação. O verde separa Bajo Belgrano da cidade existente, diferenciando-a como pedaço de "cidade futura". Em Barrio Sur, ao contrário, o verde é controlado pelos componentes edificados, e se limita à área central de cada um dos setores planejados. Assim, Barrio Sur aparece como mais integrado à cidade existente como observam Katzenstein et al. (1985) e também Liernur (2011). Contudo o que esta diferença coloca é que o trecho de cidade esparsamente ocupado sobre o qual Bajo Belgrano é pensado difere da ocupação densa de uma das áreas mais antigas da cidade, e que é enfrentada em Barrio Sur.

Uma consequência deste diferente tratamento do espaço aberto e verde é que Bajo Belgrano se faz menos denso que Barrio Sur, apresentando 295 habitantes por hectare, frente a 2.250. Esta densidade é ocupada em Bajo Belgrano por vinte barras sobre pilotis espaçadas pelo território, e separadas dos edifícios que abrigam os programas de suporte à habitação. Já em Barrio Sur a densidade é distribuída entre torres, gregas e edifícios baixos, e os programas de suporte à habitação podem se misturar a essas tipologias, expandido as possibilidades de ocupação do nível térreo. Assim, de Bajo Belgrano para Barrio Sur há uma ampliação quanto às experimentações possíveis para as tipologias habitacionais, bem como a diversificação entre programas que coincidem em um mesmo tipo.

\section{Conclusão}

Visando o tema do congresso, bem como o respectivo eixo temático "Discurso Profissional", este texto procurou confrontar duas proposições não construídas de que Antonio Bonet Castellana participa, referidas pelo arquiteto como discursos relacionados. Este texto não esgota as relações possíveis entre estes projetos, mas constitui um começo, contribuindo para

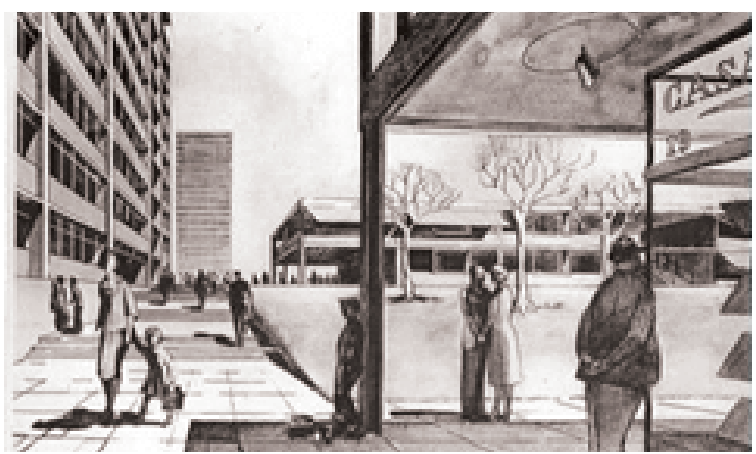

um estudo mais detalhado sobre a cidade moderna. Como resposta à pergunta inicial, tem-se que entre Bajo Belgrano e Barrio Sur o que há em comum não são componentes exatos, os quais diferem em suas especificidades, mas estratégias de projeto, vinculadas à cidade existente ao mesmo tempo em que revisam suas estruturas.

Assim a quadra tradicional é reorganizada em novas parcelas, cujo sistema viário é ampliado e as circulações entre veículos e pedestres separadas. Contudo tais parcelas não são equivalentes entre si, existindo em Bajo Belgrano uma abstração maior do que em Barrio Sur, já que os componentes edificados daquela proposição deixam de coincidir com a parcela desenhada para se orientar conforme outra lógica. Da mesma maneira, tanto Bajo Belgrano quanto Barrio Sur organizam centros comerciais e sistemas de percursos pedestres preenchidos de programas e elementos. Tais características são aqui destacadas como contribuições importantes para o estudo da cidade moderna, organizando um espaço aberto diferente da ideia de blocos soltos sobre o verde, comumente associada a essas proposições ou ao discurso CIAM. Porém cada sistema pedestre é pensado de forma distinta: ainda que a preocupação de ambos seja com o grande espaço aberto, o sistema montado para Barrio Sur se realiza de forma mais expandida, distribuindo-se sobre o território em vez de se limitar a uma estrutura unitária.

Dessa maneira, o verde contínuo de Bajo Belgrano é controlado quando aplicado em Barrio Sur, diferença que também se desdobra em concentrações distintas. Esse predomínio de áreas abertas em Bajo Belgrano ou de áreas construídas em Barrio Sur pode ser relacionado com as abordagens inseridas no marco CIAM, mas também pode ser entendido em relação à cidade que existe, já que o tecido comum entre estes pedaços de cidade moderna responde a diferentes contextos. Assim, Barrio Sur se 
desenvolve como cidade concentrada por cima da cidade constituída, ao passo que Bajo Belgrano se dá sobre o vazio e reivindica o verde como elemento compositivo.

\section{Referências}

ABOY, R. Ciudad, espacio doméstico y prácticas de habitar en Buenos Aires en la década de 1950: una mirada a los departamentos para las clases medias. Nuevo Mundo Mundos Nuevos, Debates, 2010. Disponível em: <http://nuevomundo.revues.org/59215>. Acesso em: $13 \mathrm{dez}$. 2013.

ALVAREZ, F. El sueño moderno en Buenos Aires (1930-49). 1991. 477 f. Tese (Doutorado em Arquitetura) - Departamento de Composição Arquitetônica, Universidade Politécnica da Catalunha, Barcelona, 1991.

ALVAREZ, F.; ROIG, J. Antoni Bonet Castellana 1913-1989. Barcelona: Colegio de Arquitectos de Catalunya/Ministério de Fomento, 1996.

BALLENT, A. Las huellas de la política: vivienda, ciudad y peronismo en Buenos Aires, 1943-1955. Bernal: Universidade Nacional de Quilmes: Prometeo 3010, 2009.

BANCO HIPOTECARIO NACIONAL. Plan de Remodelación de la zona sudeste de la Capital Federal: estudio urbanístico, legal y financiero. Buenos Aires, 1957.

BOBZIN, A. Encuentros: Antonio Bonet. Dos Puntos, Buenos Aires, n. 10, p. 43-51, julho 1983.

BONET, A. Plan de Remodelamiento de la Zona Sud de Buenos Aires. Mirador, Buenos Aires, n. 2, p. 63-77, jun. 1957.

Remodelamiento de la zona sur de Buenos Aires. Cuadernos de Arquitectura, Barcelona, n. 37, p. 8-13, jul.-set. 1959.

CABRAL, C. P. C. Uma máquina para jogar em Buenos Aires - 1938-1978. ARQTEXTO, Porto Alegre, n. 17, p. 47-60, 2010.

CIAM. The heart of the city: towards the humanisation of urban life. Londres: Lund Humphires, 1952.

EPBA. 3a. Fundación de Buenos Aires. Vigor: EBPA, 1949a.

Exposición de Urbanismo. In: CONGRESSO HISTÓRICO-MUNICIPAL INTERAMERICANO, 4., 1949. Anais... Buenos
Aires: Municipalidad de la Ciudad de Buenos Aires, out. 1949b.

. Urbanización del Bajo de Belgrano: un barrio para 50.000 habitantes. Revista de Arquitectura, Buenos Aires, n. 369, p. 17-75, 1953.

KATZENSTEIN, E. et al. Antonio Bonet: arquitectura y urbanismo en el Río de la Plata y España. Buenos Aires: Espacio Editora, 1985.

LE CORBUSIER. Urbanisme. Paris: G. Gres, 1924.

LIERNUR, J. F. Las "villas miseria", el "Barrio Sur" y la "Revolución Libertadora". Una aproximación a la más importante propuesta de vivienda colectiva de Antonio Bonet. In: SHIMDT, C.; IBARLÚCIA, R. (Ed.). 1as Jornadas de Historia y Cultura de la Arquitectura y de la Ciudad. Historia, Estetica y Teorías de la Arquitectura: grandes obras de la arquitectura en la Argentina (1910-1980). Buenos Aires: Universidad Torcuato di Tella, 2011. p. 84-99.

PETRINA, A. Reportaje: Antonio Bonet, o el espíritu del Movimiento Moderno. Summa, Buenos Aires, n. 188, p. 19-22, jun. 1983.

PROJETO de Remodelação da Zona Sul de Buenos Aires. Antonio Bonet. Módulo, Rio de Janeiro, n. 7, p. 32-35, fev. 1957.

PROJETO de Urbanização para Buenos Aires. Habitat, Rio de Janeiro, n. 47, p. 62-75, mar.-abr. 1958.

RAMOS, I. Noticia sobre urbanismo. Revista Nacional de Arquitectura, Madri, n. 178, p. 3539, out. 1956.

SERT, J. L. Can our cities survive? An ABC of urban problems, their analysis, their solutions. Cambridge: The Harvard University Press, 1947.

SLUM-SANIERUNG in Buenos Aires. Bauen und Wohnen, Munique, n. 3, p. 74-78, mar. 1958. 
